\section{Irsyad Sudirman}

Dosen Jurusan Ilmu Administrasi

Negara

Universitas Kalimantan Utara

Email : irs_20032000@yahoo.com
PENGEMBANGAN SUMBER DAYA MANUSIA DALAM MANJEMEN BENCANA

https://doiorg//0.18196/jgpp.4385

\begin{abstract}
ABSTRAK
Penelitian ini bertujuan untuk mengetahui Model Kemitraan tentang Tata Ruang Terbuka Hijau (RTH) Hutan Kota Bunda Hayati di Tanjung Selor Kalimantan Utara. Penelitian ini menggambarkan belum effektifnya pengelolaan Hutan Kota Bunda Hayati. Serta terdapat stakeholders yang terlibat melakukan kerjasama dalam mengelola Hutan Kota Bunda Hayati.

Metode penelitian menggunakan pendekatan deskriptif kualitatif dengan menggunakan jenis data primer dan sekunder. Metode pengumpulan data dengan cara wawancara dan dokumentasi data sekunder. Hasil penelitian ini menunjukan Model Kemitraan Solid dengan melibatkan Intitut Pertanian Bogor (IPB) sebagai mitra. Model Kemitraan Solid menggambarkan jejaring diantara pihak stakeholders dengan pemerintah daerah dalam pengelolaan Hutan Kota Bunda Hayati. Kerjasama tersebut menghasilkan Master Plan pembangunan Hutan Kota Bunda Hayati.
\end{abstract}

Kata kunci : Ruang Terbuka Hijau, Hutan Kota Bunda Hayati, Model Kemitraan Solid

\title{
PENdAhUluaN
}

Undang-Undang Nomor 32 Tahun 2004 tentang Pemerintahan Daerah memacu pembangunan daerah secara simultan. Jika Pembangunan daerah telah berlangsung serta berjalan dengan pesat dan akan terus berlanjut, maka diperkirakan akan terjadi perubahan pola pemanfaatan ruang. Kewenangan pemerintah daerah tentang penataan ruang terdapat pada Pasal 3 Undang-Undang Nomor 26 Tahun 2007 tentang Penataan Ruang, yang menyatakan bahwa penataan ruang perkotaan diselenggarakan untuk mewujudkan ruang wilayah nasional yang aman, nyaman, produktif, dan berkelanjutan dengan :

a. Terwujudnya keharmonisan antara lingkungan alam dan lingkungan buatan.

b. Terwujudnya keterpaduan dalam penggunaan sumber daya alam dan sumber daya buatan dengan memperhatikan sumber daya manusia.

c. Terwujudnya perlindungan fungsi ruang dan pencegahan dampak negatif terhadap lingkungan akibat pemanfaatan ruang.

Berdasarkan pemahaman tersebut, maka salah satu masalah yang berkaitan dengan penataan ruang adalah permasalahan ruang terbuka hijau di wilayah perkotaan, yang manjadi tanggung jawab pemerintah Kabupaten/Kota. Permasalahan pengelolaan ruang terbuka hijau oleh Pemerintah Daerah sebagai bagian integral pembangunan daerah, sebagaimana diatur dalam Peraturan Pemerintah Republik Indonesia Nomor 63 Tahun 2002 tentang Hutan Kota. 
Dewasa ini ruang terbuka hijau (RTH) wilayah perkotaan merupakan bagian dari penataan ruang kota yang berfungsi sebagai kawasan hijau pertamanan kota, kawasan hijau hutan kota, kawasan hijau rekreasi kota, kawasan hijau kegiatan olahraga dan kawasan hijau pekarangan. Pemanfatan ruang terbuka hijau (RTH) lebih bersifat pengisian hijau tanaman atau tumbuh-tumbuhan secara alamiah ataupun budidaya tanaman seperti Fungsi dari tumbuh-tumbuhan yang sangat erat kaitannya dengan kesehatan manusia, sehingga dalam tata ruang kota, pemanfaatan tumbuhtumbuhan yang biasanya berbentuk taman kota, ruang terbuka kota, jalur hijau dan sebagainya, sering disebut sebagai paru-paru kota (Anggraini, 1998).

Permasalahan pembangunan daerah oleh pemerintah daerah dewasa ini di Indonesia haruslah bertujuan dan mengacu pada konsep-konsep Sustainable Development, karena berkaca dari kondisi wilayah perkotaan di kota-kota besar di Indonesia, seperti Jakarta, Surabaya, Semarang, Medan dan Bandung dimana banyak konsep pembangunan daerah yang mengacuhkan konsep-konsep ramah lingkungan yang berdampak pada area pemukiman kota itu sendiri. Salah satu dampak nyata adalah banjir besar yang melanda Kota Jakarta pada akhir tahun 2012 dan awal tahun 2013 lalu. Demikian pula halnya dengan konsep penataan ruang kota dan ruang terbuka hijau (RTH) di Tanjung Selor, terutama sejak ditetapkan sebagai Ibukota Provinsi Kalimantan Utara dan juga sekaligus sebagai Ibukota Kabupaten Bulungan. Bahwasannya Tanjung Selor kedepannya secara otomatis memiliki potensi pertumbuhan sebagai kota besar, yang sudah pasti membutuhkan pola perencanaan tata ruang kota yang terkontrol dan terkoordinasi dengan baik.

Fakta menunjukan bahwa pola pemanfaatan ruang terbuka hijau di Kabupaten Bulungan baru sebatas luasan lahan Hutan Kota Bunda Hayati sebesar 86 ha saja yang dijadikan ruang terbuka hijau atau hanya sekitar 0,56 persen saja yang dijadikan RTH. Sedangkan jika mengacu pada Undang-Undang Nomor 26 Tahun 2007 tentang Penataan Ruang maupun mengacu pada Peraturan Pemerintah Nomor 63 Tahun 2002 tentang Hutan Kota, Tanjung Selor sudah seharusnya memiliki hutan kota minimal 247,5 ha. Namun demikian dengan luasan hutan kota yang ada sekarang yang hanya seluas 86,28 ha, sudah seharusnya pemerintah daerah berfokus pada pembangunan, pengembangan dan pengelolaannya tanpa mengabaikan kebutuhan terhadap kondisi minimnya perencanaan ruang terbuka hijau (RTH) lainnya. 
Penelitian ini berupaya memberikan gambaran tentang sistem pengelolaan ruang terbuka hijau dengan Model Kemitraan secara lebih efektif, yang selama ini tidak dilakukan secara komprehensif oleh Pemerintah Daerah. Apa yang menjadi gambaran selama ini adalah lahan Hutan Kota Bunda Hayati yang dalam pengelolaannya cenderung diabaikan dikarenakan oleh permasalahan-permasalahan yang sangat kompleks. Sedangkan Peraturan Daerah Nomor 12 Tahun 1995 tentang Pemanfaatan dan Pengelolaan Hutan Kota Bunda Hayati telah jelas peruntukannya sebagai bagian dari konsep paru-paru kota yang kedepannya akan dijadikan model pengembangan dan pengelolaan kota yang lebih ramah lingkungan.

Berdasarkan beberapa fakta latar belakang di atas, maka penelitian ini berusaha mengidentifikasi dan menjelaskan fenomena lebih lanjut tentang Hutan Kota Bunda Hayati dalam bentuk pertanyaan berikut :

Bagaimanakah Penerapan Model Kemitraan antara Masyarakat dan Pemerintah Daerah dalam Pengelolaan Hutan Kota Bunda Hayati Di Tanjung Selor Kabupaten Bulungan Provinsi Kalimantan Utara?

\section{A. TINJAUAN PUSTAKA \\ Ruang Terbuka Hijau (RTH)}

Ruang terbuka (open spaces), Ruang Terbuka Hijau (RTH), Ruang publik (public spaces) mempunyai pengertian yang hampir sama. Secara teoritis yang dimaksud dengan ruang terbuka (open spaces) adalah Ruang yang berfungsi sebagai wadah (container) untuk kehidupan manusia, baik secara individu maupun berkelompok, serta wadah makhluk lainnya untuk hidup dan berkembang secara berkelanjutan (UUPR No.24/1992). Budihardjo (1999:90) berpendapat ruang terbuka hijau adalah suatu wadah yang menampung aktivitas manusia dalam suatu lingkungan yang tidak mempunyai penutup dalam bentuk fisik. Kemudian Gallion (1959:282) memberikan pengertian ruang terbuka hijau sebagai ruang yang berfungsi antara lain sebagai tempat bermain aktif untuk anak-anak dan dewasa, tempat bersantai pasif untuk orang dewasa, dan sebagai areal konservasi lingkungan hijau.

Sedangkan Adams (1952:156) menjelaskan bahwa ruang terbuka hijau adalah ruang yang berdasarkan fungsinya sebagai ruang terbuka hijau yaitu dalam bentuk taman, lapangan atletik dan taman bermain. Pendapat lain dari Green (1962) yang menyatakan ruang terbuka hijau adalah lahan yang belum dibangun atau sebagian besar belum dibangun di wilayah perkotaan yang mempunyai nilai untuk keperluan taman dan rekreasi; 
konservasi lahan dan sumber daya alam lainnya; atau keperluan sejarah dan keindahan. Dalam perkembangan tentang RTH, agar menjadi jelas peruntukannya. Maka di Indonesia dilakukan klasifikasi atas nilai intrinsik dari RTH tersebut dibangun. Klasifikasi RTH atas dasar nilai kegunaannya, menurut Instruksi Menteri Dalam Negri Nomor 14 tahun 1988, yaitu berupa : taman kota, lapangan olah raga, kawasan hutan kota, jalur hijau kota, perkuburan, pekarangan, dan RTH produktif. Bentuk RTH yang memiliki fungsi paling penting bagi perkotaan sejak Tahun 2008 adalah kawasan hijau taman kota dan kawasan hijau lapangan olah raga. Taman kota dibutuhkan karena memiliki hampir semua fungsi RTH, sedangkan lapangan olah raga hijau memiliki fungsi sebagai sarana untuk menciptakan kesehatan masyarakat selain itu bisa difungsikan sebagian dari fungsi RTH lainnya. Adapun fungsi dari RTH bagi kota adalah untuk meningkatkan kualitas kehidupan dan lingkungan dalam kota dengan sasaran untuk memaksimumkan tingkat kesejahteraan warga kota dengan menciptakan lingkungan yang lebih baik dan sehat.

Pada dasarnya RTH kota mempunyai 3 fungsi dasar yaitu :

1) Berfungsi secara sosial yaitu fasilitas untuk umum dengan fungsi rekreasi, pendidikan dan olahraga. Dan menjalin komunikasi antar warga kota.

2) Berfungsi secara fisik yaitu sebagai paru-paru kota, melindungi sistem air, peredam bunyi, pemenuhan kebutuhan visual, menahan perkembangan lahan terbangun sebagai penyangga, melindungi warga kota dari polusi udara.

3) Berfungsi sebagai estetika yaitu pengikat antar elemen gedung dalam kota, pemberi ciri dalam membentuk wajah kota dan unsur dalam penataan arsitektur perkotaan. Sangat penting untuk diingat bahwa tumbuhan merupakan kehidupan pelopor yang menyediakan bahan makanan dan perlindungan kepada hewan maupun manusia. Sementara untuk kota di luar negeri taman identik dengan peradaban suatu bangsa, sehingga mereka sangat memperhatikan masalah pembangunan fungsi.

\section{KEMITRAAN}

Menurut Notoatmodjo (2003), kemitraan adalah suatu kerja sama formal antara individu-individu, kelompok-kelompok atau organisasiorganisasi untuk mencapai suatu tugas atau tujuan tertentu. Menurut Ditjen 
P2L \& PM (2004) terdapat 3 prinsip kunci yang perlu dipahami dalam membangun suatu kemitraan oleh masing-masing anggota kemitraan yaitu :

1. Prinsip Kesetaraan (Equity)

Individu, organisasi atau institusi yang telah bersedia menjalin kemitraan harus merasa sama atau sejajar kedudukannya dengan yang lain dalam mencapai tujuan yang disepakati.

2. Prinsip Keterbukaan

Keterbukaan terhadap kekurangan atau kelemahan masing-masing anggota serta berbagai sumber daya yang dimiliki. Semua itu harus diketahui oleh anggota lain. Keterbukaan ada sejak awal dijalinnya kemitraan sampai berakhirnya kegiatan. Dengan saling keterbukaan ini akan menimbulkan saling melengkapi dan saling membantu diantara golongan (mitra).

3. Prinsip Azas manfaat bersama (mutual benefit)

Individu, organisasi atau institusi yang telah menjalin kemitraan memperoleh manfaat dari kemitraan yang terjalin sesuai dengan kontribusi masing-masing. Kegiatan atau pekerjaan akan menjadi efisien dan efektif bila dilakukan bersaman. Kemitraan memberikan nilai tambah kekuatan kepada masing-masing sektor untuk melaksanakan visi dan misinya.

Namun kemitraan juga merupakan suatu pendekatan yang memerlukan persyaratan, untuk itu diperlukan langkah-langkah tahapan sebagai berikut :

a. Pengenalan masalah.

b. Seleksi masalah.

c. Melakukan identifikasi calon mitra dan pelaku potensial melalui suratmenyurat, telepon, kirim brosur, rencana kegiatan, visi, misi, AD/ART.

d. Melakukan identifikasi peran mitra/jaringan kerjasama antar sesama mitra dalam upaya mencapai tujuan, melalui : diskusi, forum pertemuan, kunjungan kedua belah pihak, dll.

e. Menumbuhkan kesepakatan yang menyangkut bentuk kemitraan, tujuan dan tanggung jawab, penetapan rumusan kegiatan memadukan sumberdaya yang tersedia di masingmasing mitra kerja, dll. Kalau ini sudah ditetapkan, maka setiap pihak terbuka. kesempatan untuk melaksanakan berbagai kegiatan yang lebih bervariasi sepanjang masih dalam lingkup kesepakatan.

f. Menyusun rencana kerja : pembuatan POA penyusunan rencana kerja dan jadwal kegiatan, pengaturan peran, tugas dan tanggung jawab. 
g. Melaksanakan kegiatan terpadu : menerapkan kegiatan sesuai yang telah disepakati bersama melalui kegiatan, bantuan teknis, laporan berkala, dll.

h. Pemantauan dan evaluasi.

Ruang lingkup kemitraan secara umum meliputi pemerintah, dunia usaha, LSM/ORMAS, serta kelompok profesional. Secara umum menurut Notoadmodjo (2007), model kemitraan dapat dikelompokkan menjadi dua yaitu :

\section{1) Model I}

Model kemitraan yang paling sederhana adalah dalam bentuk jaring kerja (networking) atau building linkages. Kemitraan ini berbentuk jaringan kerja saja. Masing-masing mitra memiliki program tersendiri mulai dari perencanaannya, pelaksanaannya hingga evalusi. Jaringan tersebut terbentuk karena adanya persamaan pelayanan atau sasaran pelayanan atau karakteristik lainnya.

\section{2) Model II}

Kemitraan model II ini lebih baik dan solid dibandingkan model I. Hal ini karena setiap mitra memiliki tanggung jawab yang lebih besar terhadap program bersama. Visi, misi, dan kegiatan-kegiatan dalam mencapai tujuan kemitraan direncanakan, dilaksanakan, dan dievaluasi bersama.

\section{METODE PENELITIAN}

Metode yang digunakan dalam penelitian ini memakai tipe dan jenis penelitian Kualitatif atau metode deskriptif kualitatif. Penelitian deskriptif merupakan cara untuk memahami fenomena sosial, berupa serangkaian kegiatan atau upaya menjaring informasi secara mendalam dari permasalahan yang ada dalam kehidupan suatu objek, dihubungkan dengan pemecahan suatu masalah, baik dari sudut pandang teortis maupun empiris. Metode ini dipakai untuk mengamati secara sistematis, faktual dan akurat mengenai fakta-fakta dan sifat-sifat yang terjadi di lapangan.

Penelitian ini berusaha mengamati dan mengungkap realitas yang terjadi di lapangan. Berkaitan dengan Studi Model Kemitraan dalam Pengelolaan Hutan Kota Bunda Hayati di Tanjung Selor. Dalam model penelitian yang dilaksanakan tidak harus berhadapan dengan fakta secara langsung namun juga menguji nilai obyektifitas dari hasil keterangan yang 
didapat dari narasumber, dan kemudian diujikan kembali melalui telaah kepustakaan, internet, buku-buku, majalah dan Koran. Dengan tujuan untuk mencapai derajat kebenaran yang mendekati fakta empiris di lapangan. Penentuan lokasi penelitian, khusus ditujuakan kepada tiga instansi yang terkait : Pertama, Penelitian ini menggambil lokasi di lingkungan Suku Dinas Kehutanan Kabupaten Bulungan; Kedua, Penelitian akan menggambil lokasi pada Lahan Hutan Kota Bunda Hayati; dan yang Ketiga, Lokasi Penelitian dipusatkan di Ibukota Tanjung Selor, yang dianggap sebagai pusat kegiatan penelitian. Penelitian ini menggunakan jenis data primer dan sekunder, artinya bahwa penelitian ini menekankan penggalian data secara mendalam melalui sumber-sumber yang tertulis dan wawancara yang mendalam dengan narasumber.

Penelitian ini menganalisa studi model kemitraan dalam pengelolaan Hutan Kota Bunda Hayati di Tanjung Selor Kabupaten Bulungan Kalimantan Utara. Analisa terhadap fenomena atau gejala awal yang dilakukan dimulai dari kondisi yang abstrak dengan sebuah pertanyaan bagaimana kemungkinan studi model kemitraan dalam pengelolaan hutan kota Bunda Hayati di Tanjung Selor dapat dilaksanakan. Untuk itu, maka indikator keberhasilan yang dipakai sebagai analisis berupa :

a. Input atau Masukan data terkait informasi :

1) Faktor-faktor yang mempengaruhi Model Kemitraan, yang terdiri atas :

I. Faktor Dukungan Masyarakat

II. Faktor Kesiapan Pemerintah Daerah

III. Faktor Lokasi Kawasan Hutan Kota Bunda Hayati pembangunan kota.

b. Proses data hasil input yang mendiskripsikan tentang :

1) Model Kemitraan Jaring Kerja, yang terdiri atas :

I. Bentuk Pengawasan Pengelolaan Hutan Kota Bunda Hayati.

II. Persepsi Tingkatan Regulasi

c. Model Kemitraan Solid

1) Kelembagaan

2) Kebijakan Pengembangan Hutan Kota Bunda Hayati

3) Output berupa : Dampak lingkungan yang muncul berupa Sustainable Development. Beberapa poin tersebut akan menjadi ukuran dalam melihat bagaimana kemungkinan Model Kemitraan Dapat Diterapkan Dalam Pengelolaan Hutan Kota Bunda Hayati Tanjung Selor Kabupaten Bulungan Kalimantan 
KERANGKA PIKIR

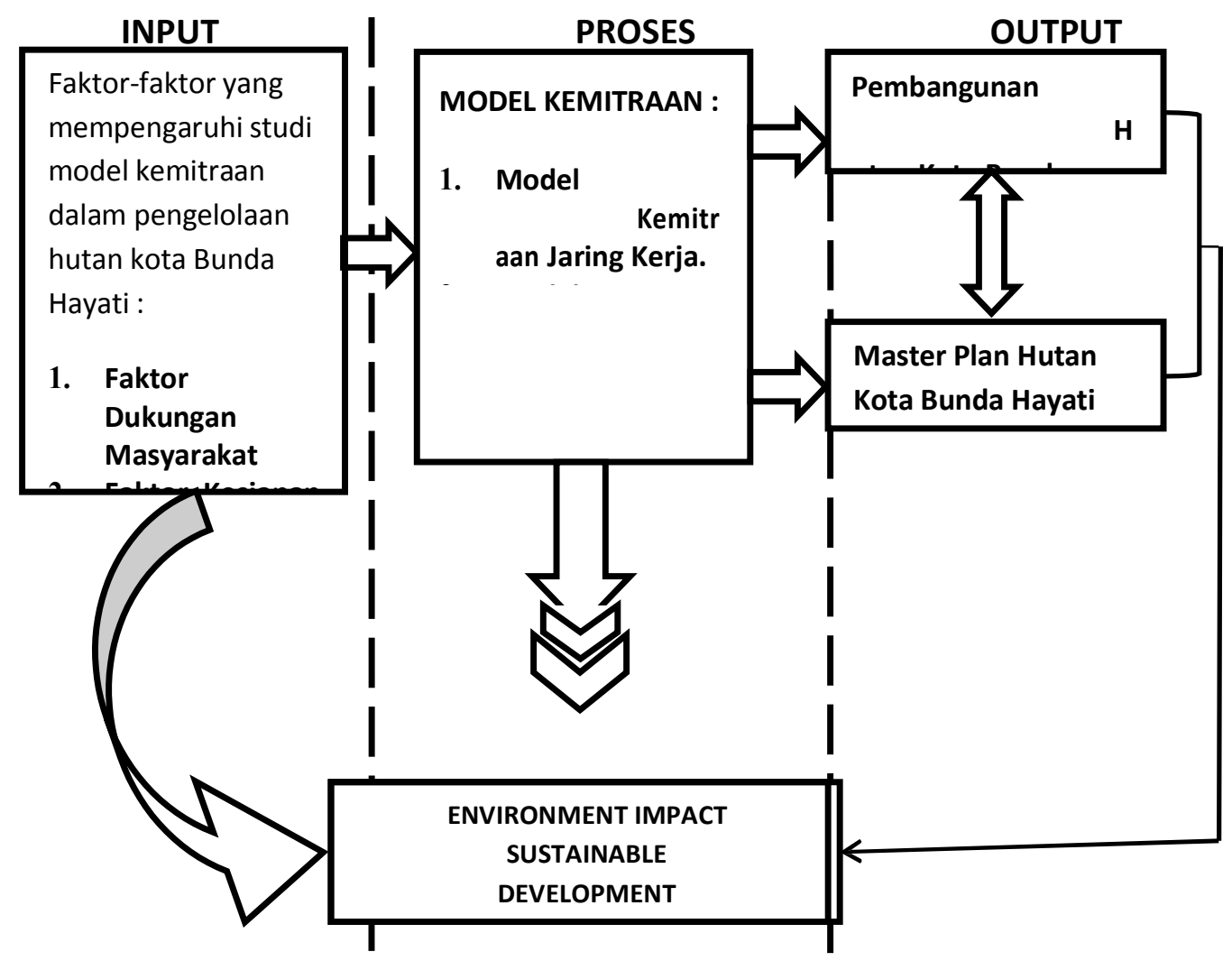

Penelitian tentang Ruang Terbuka Hijau (RTH) masih sangat minim dalam pembahasan disiplin ilmu-ilmu politik pemerintahan, dikarenakan sifat pembahasan terkait Ruang Terbuka Hijau (RTH) lebih cenderung masuk ke ranah disiplin ilmu Planologi yang berada pada bidang keilmuan Teknik. Seperti pada penelitian yang dilakukan oleh Bambang Wijarnako, di mana peneliti menggunakan pendekatan teori partisipatif dalam model pengelolaan wilayah pesisir pantai Utara kota Surabaya. Obyek model pengelolaan ruang terbuka hijau yang dicermati oleh Bambang adalah pada sisi kerjasama partisipatif antara pemerintah Kota Surabaya dengan masyarakat wilayah pesisir Utara Kota Surabaya. Model partisipatif berdasarkan hasil penelitian Bambang, lebih mendekatkan upaya pemberdayaan masyarakat lokal agar lebih perduli terhadap kondisi 
lingkungan wilayah pesisir. Sedangkan, penelitian yang dilakukan oleh 6 (Enam) peneliti lainnya seperti Sumarmi (2006), Emma Wulandari (2007), Oman Sukmana (2007), Gunung Haryadi Ndaru Nugroho (2010), José Manuel Maniquin (2011), Ernady Syaodih \& Weisyaguna (2011) yang menyatakan bahwa tingkat partisipasi masyarakat dalam pengelolaan RTH masih rendah. Kesemua peneliti tersebut lebih banyak menekankan pada pola prilaku human development.

\section{HASIL DAN PEMBAHASAN}

\section{Analisis Model Kemitraan Jaring Kerja}

Model Kemitraan Jaring Kerja dalam pengelolaan Hutan Kota Bunda Hayati Tanjung Selor lebih cenderung melihat kondisi pengelolaan kawasan Hutan Kota Bundayati dalam bentuk jaring kerja (networking) atau building linkages. Berdasarkan tata kerja sebagaimana di sebutkan dalam Perda 12/95 Pasal 3 ayat 3 dan Sk Bupati 62/98 Pasal 3 terdapat 5 instansi yang berwenang dalam pengelolaan Hutan Kota Bunda Hayati, yakni :

1) Dinas Pekerjaan Umum Daerah Tingkat II Bulungan

2) Instansi Dinas Kehutanan di Wilayah Kabupaten

3) Dinas Pariwisata Daerah Tingkat II Bulungan

4) Dinas Perkebunan Daerah Tingkat II Bulungan

5) Dinas/instansi terkait lainnya.

Terkait dengan permasalahan di atas, maka pada tahun 2003 dikeluarkan Peraturan Daerah Nomor 5 Tahun 2003 tentang Rencana Umum Tata Ruang Wilayah (Rutrw) Kabupaten Bulungan Tahun 2001 2010. Dalam Perda ini pada BAB VI tentang Pelaksanaan Rencana Umum Tata Ruang Wilayah Pasal 15 secara rinci di atur :

1) Kawasan budidaya kehutanan adalah kawasan hutan atau wilayah tertentu yang ditetapkan oleh pemerintah sebagai hutan mencakup :

a. Hutan Produksi Tetap (HPT)

b. Hutan Produksi Terbatas (HP).

2) Kawasan budidaya kehutanan harus dapat dikukuhkan melalui proses penetapan batas, pemetaan dan penetapan kawasan hutan. 3. Selain kawasan budidaya kehutanan, juga dikenal kawasan antara lain :

a. Kawasan Hutan Kota

b. Kawasan Penyanggah. 
c. Kawasan Hutan Kota terdapat di Tanjung Selor dengan luas $86,86 \mathrm{Ha}$

d. Kawasan-kawasan dimaksud dilakukan pemetaan batas kawasan hutan

e. Pemetaan dan penetapan batas kawasan hutan diketuai oleh Bupati dan unsur-unsur terkait

f. Kawasan penyanggah merupakan kawasan yang berfungsi sebagai hidrolis dengan kriteria :

a. Kawasan dengan kelerengan $25-40 \%$

b. Kawasan disekitar kawasan lindung denga radius lebih kurang 2000 m; c. Kawasan dengan ketinggian 1000 m

d. Kawasan disekitar mata air dengan radius $200 \mathrm{~m}$

e. Kawasan pantai dari air surut terendah lebuh kurang $100 \mathrm{~m}$

f. Kawasan kiri kanan anak sungai lebih kurang $50 \mathrm{~m}$.

\section{KEGIATAN PENGELOAAN HUTAN KOTA}

Sejak dikeluarkannya Perda Nomor 12 Tahun 1995 yang kemudian ditindaklanjuti dengan Keputusan Bupati Nomor 62 Tahun 1998 terdapat banyak instansi pemerintah yang turun tangan melaksanakan pengelolaan Hutan Kota Bunda Hayati. Sasaran kegiatan pengeloaan yang telah dilakukannya lebih bersifat persiapan fisik untuk mewujudkan kepastian keberadaan lokasi hutan kota. Instansi-instansi yang mendapat tugas melaksanakan kegiatan persiapan tersebut, dalam koordinasi dan pengendalian Bappeda adalah :

1) Bapeda melakukan kegiatan pemagaran kawasan dan penghijauan (penanaman pohon) melalui kerjasama dengan Kantor Pemberdayaan Perempuan.

2) Sekretariat Daerah membantu Bupati melaksanakan pembebasan hutan.

3) Dinas Pekerjaan Umum melakukan kegiatan pembuatan saluran drainase.

4) Kantor Satuan Polisi Pamong Praja (Satpol PP) dibantuk Resor Kepolisian melakukan kegiatan pengamanan kawasan. Sejak tahun 2002, Dinas Kehutanan secara khusus diserahi wewenang untuk menjalankan kegiatan pengelolaan Hutan Kota Bunda Hayati. Pengelolaan Hutan Kota Bunda Hayati yang telah dilaksanakan oleh instansi Dinas Kehutanan adalah penghijauan dan reboisasi, mewakili BP-DAS, dalam 
rangka program GNRHL. Dalam struktur Dinas Kehutanan, kegiatan reboisasi dan penghijaua ini ditangani oleh Sub Dinas Produksi dan Bina Hutan. Pengadaan bibit tanaman ditangani BP-DAS, instansi daerah yang berwenang melakukan penghijauan. Penyelenggaraan penanaman menggunakan tenaga kerja masyarakat melalui kerjasama dengan Pemda Kecamatan dan Kelurahan/Desa serta dengan Kantor Pemberdayaan Perempuan, dan lembaga masyarakat PKK melalui program "Gerakan Perempuan Menanam".

\section{BENTUK PENGAWASAN PENGELOLAAN HUTAN KOTA BUNDA HAYATI}

Hutan kota selain berfungsi untuk pengendalian lingkungan, terutama dalam hal pengendalian kualitas udara, pengawetan tanah dan tata air, serta pengerndalian iklim mikro, juga dapat berfungsi konservasi keanekaragaman hayati, pendidikan lingkungan, penelitian, kebudayaan serta kepariwisataan dan rekreasi. Dalam hal kaitan dengan pewujudan fungsifungsi tersebut, maka berbagai kegiatan pembangunan dan pengelolaan hutan kota dapat diselenggarakan dengan melibatkan peran serta segenap lembaga atau unsur masyarakat yang ada. Pelibatan segenap lembaga atau unsur masyarakat perlu dilakukan, dan merupakan hal penting karena akan lebih berarti dalam membangun rasa kebersamaan dan persatuan.

Tabel 1.

Hubungan keterkaitan Fungsional Institusi di Kabupaten Bulungan dengan Pembangunan dan Pengelolaan Hutan Kota Bunda Hayati

\begin{tabular}{|c|l|l|l|l|l|l|l|}
\hline \multirow{2}{*}{ No } & \multicolumn{2}{|c|}{ Institusi } & \multicolumn{5}{|c|}{ Fungsi Hutan Kota } \\
\hline & & a & b & c & d & e & f \\
\hline 1 & Kehutanan & & & & & & \\
\hline 2 & Pertanian & & & & & & \\
\hline 3 & Peternakan & & & & & & \\
\hline 4 & Diknas & & & & & & \\
\hline 5 & P. Tinggi, sekolah & & & & & & \\
\hline 6 & PU & & & & & & \\
\hline 7 & BKSDA & & & & & & \\
\hline 8 & BP DAS & & & & & & \\
\hline 9 & Kesehatan & & & & & & \\
\hline 10 & Sosial & & & & & & \\
\hline 11 & Bapedalda & & & & & \\
\hline
\end{tabular}




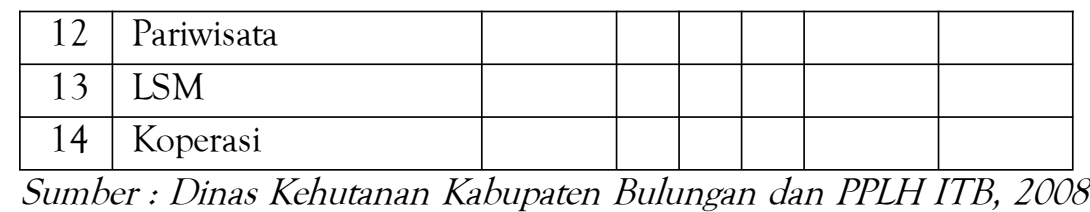

Keterangan :

a : Konservasi, Perlindungan dan Lingkungan

b : Penelitian

c : Pendidikan

d : Kebudayaan/Budidaya

e : Pariwisata/rekreasi $f$ : Layanan

\section{ANALISIS MODEL KEMITRAAN SOLID}

Model Kemitraan solid mengharuskan setiap mitra memiliki tanggung jawab yang lebih besar terhadap program bersama. Visi, misi, dan kegiatan-kegiatan dalam mencapai tujuan kemitraan direncanakan, dilaksanakan, dan dievaluasi bersama.

Pola Kemitraan Solid dalam pengelolaan Hutan Kota Bunda Hayati Tanjung Selor sejak keluarnya Perda No. 12/1995 dan KepBup No. 62/1998 belum terlaksana secara baik, walaupun secara konseptual telah berusaha di implementasikan kearah itu. Kondisi ini tentu menjadi hal penting untuk segera di implementasikan, apalagi dengan seiring keluarnya Undang-Undang Nomor 20 Tahun 2012 tentang Pembentukan Provinsi Kalimantan Utara, terutama pada Pasal 7.

Ada beberapa hal yang menjadi alasan mengapa pengembangan, pengelolaan dan perencanaan Hutan Kota Bunda Hayati sangat penting untuk di implementasikan dan bukan sekedar muncul di tataran konseptual sebagaimana telah dilaksanakan oleh Dishut bersama IPB, yakni :

1) Kepastian lokasi Hutan Kota Tanjung Selor berdasarkan Surat Keputusan Bupati No. 62 tahun 1998 dengan luas 90,2 ha. Setelah dilakukan penataan batas dan pengukuran ulang di lapangan, maka luasnya menjadi 86,28 ha.

2) Hutan Kota Bunda Hayati terletak di lokasi yang strategis yaitu di tengah-tengah Kota Tanjung Selor dengan aksesibilitas yang tinggi.

3) Di beberapa bagian dari hutan kota ini sudah terdapat area yang ditumbuhi vegetasi, baik pada tingkat semai, pancang, tiang maupun pohon sehingga membuat lingkungan menjadi sejuk dan nyaman. 
4) Hutan Kota Bunda Hayati sebagai habitat beberapa jenis tumbuhan yang dilindungi. Penunjukan kawasan sebagai hutan kota memungkinkan dilakukan pengembangan berbagai fungsi, meliputi perlindungan, rekreasi, pendidikan dan sosial budaya.

5) Berdasarkan wawancara dengan sebagian komponen masyarakat terutama pemuka masyarakat menyatakan setuju pembangunan dan penataan hutan kota.

6) Adanya kebutuhan tempat rekreasi yang mudah dijangkau masyarakat Kota Tanjung Selor.

7) Jumlah penduduk yang terus meningkat dan sebesar $60 \%$ diantaranya tergolong sejahtera yang berpotensi sebagai pemanfaat hutan kota untuk rekreasi.

8) Kemajuan teknologi yang memadai dalam bidang arsitektur lansekap dan kehutanan.

9) Peraturan Daerah memungkinkan pengembangan orgnanisasi pengelolaan hutan kota.

10) Mendapatkan dana dari bagi hasil dari pengelolaan hutan produksi.

11) Kewajiban pendanaan lingkungan yang melekat pada berbagai sektor usaha (pertambangan, kehutanan dan lainnya) dapat menjadi sumber pendanaan hutan kota.

12) Mendapatkan dana dari skema mekanisme pembangunan bersih (Clean Development Mechanism).

13) Event 2 tahunan Festivas Birau yang diselenggarakan di Kota Tanjung Selor yang banyak menarik minat pengunjung masih memerlukan lokasi atraksi budaya dan kegiatan lainnya.

\section{ARAHAN PEMBUATAN MASTER PLAN HUTAN KOTA}

Penyusunan Master Plan Pembangunan Hutan Kota Bunda Hayati terlebih dahulu didasarkan pada tujuan pembangunan hutan kota itu sendiri dan obyek yang akan dilindungi. Tujuan pembangunan hutan kota didasarkan pada beberapa pertimbangan : 1. Permasalahan dan Potensi Permasalahan Lingkungan Kota Tanjung Selor. Secara umum kota Tanjung Selor sampai saat ini belum mempunyai permasalahan lingkungan yang menonjol. Menurut Bapedalda Kabupaten Bulungan (2008) bahwa :

"Kualitas udara dan kebisingan di Tanjung Selor masih memenuhi baku mutu lingkungan berdasarkan Keputusan Menteri Negara Lingkungan Hidup No. 48.MenLH/11/1996 maupun Peraturan Pemerintah No. 
41 tahun 1996 tentang Pengendalian Pencemaran Udara. Namun demikian, pada bulan-bulan tertentu yaitu pada bulan Agustus dan September seringkali terjadi kabut asap akibat pembakaran lahan perladangan yang dilakukan oleh masyarakat."

Berdasarkan rencana Detail tata Ruang kota Tanjung Selor 20072016 bahwa di sekitar kawasan Hutan Kota Bunda Hayati akan menjadi ruang terbangun baik untuk pemukiman maupun perkantoran. Hasil analisis citra landsat selama kuran waktu 5 tahun (2002-2007) ada penambahan ruang terbangun dari 9,4\% menjadi kondisi $19,2 \%$ dari luas kota. Artinya peningkatan dua kali lipat selama kurun waktu lima tahun.

\section{PROGRAM PENGEMBANGAN HUTAN KOTA}

Keberadaan hutan kota dimaksudkan untuk memperbaiki dan sekaligus meningkatkan kualitas lingkungan kota serta dapat sebagai sarana interaksi sosial yang representatif sehingga dapat memberikan manfaat yang maksimal bagi masyarakat penghuni kota. Sesuai dengan potensi dan permasalahan serta dalam upaya mewujudkan visi pengembangan Hutan Kota Bunda Hayati, maka terdapat beberapa konsep program sesuai Master Plan Hutan Kota sebagai berikut :

1. Program Rekreasi Kawasan Hutan Kota Bunda Hayati akan menjadi potensi wisata yang menarik apabila dilakukan penataan di dalamnya. Wisata sebagai sebuah sistem dapat berjalan dengan baik jika bagian-bagian dari sistem tersebut berfungsi secara efisien dan sinergis antara bagian yang satu dengan yang lainnya. Untuk itu, dalam pengembangan wisata pada umumnya, selain mempertimbangkan karakteristik demand (pengunjung potensial), juga perlu memperhatikan fungsi suplai. Suplai wisata mencakup seluruh pengembangan fisik dan program yang disediakan untuk memenuhi kebutuhan dan kepuasan pengunjung. Secara garis besar, suplai wisata mencakup aspek aktivitas, fasilitas dan pelayanan, transportasi, informasi dan promosi.

2. Konservasi Keanekaragaman Hayati Selain sebagai area konservasi eks-situ untuk vegetasi, maka kawasan Hutan Kota Bunda Hayati juga dapat dijadikan habitat satwa liar terutama burung dan monyet ekor panjang. Oleh karena itu, pada area tertentu akan dipilih jenis tanaman yang cocok untuk habitat 
satwa tersebut. Oleh karena tipe hutan kota yang dikembangkan adalah tipe rekreasi, maka jenis-jenis tanaman yang mempunyai keindahan dan keunikan akan dikembangkan, yang sekaligus juga menambah nilai keanekaragaman hayati. Pengembangan jenis-jenis estetis akan dilakukan di blok-blok intensif.

3. Pendidikan Lingkungan Pendidikan lingkungan adalah upaya mengubah perilaku dan sikap masyarakat yang bertujuan untuk meningkatkan pengetahuan, keterampilan dan kesadaran masyarakat tentang nilai-nilai lingkungan dan issue permasalahan lingkungan yang pada akhirnya dapat menggerakkan masyarakat untuk berperan aktif dalam upaya pelestarian dan keselamatan lingkungan untuk kepentingan generasi sekarang dan yang akan datang. Kawasan Hutan Kota Bunda Hayati dapat difungsikan sebagai sarana untuk pendidikan lingkungan bagi pelajar, mahasiswa maupun masyarakat yaitu sebagai laboratorium alam atau arboretum.

\section{KESIMPULAN}

Hasil penelitian Studi Model Kemitraan Dalam Pengelolaan Hutan Kota Bunda Hayati di Tanjung Selor Kabupaten Bulungan Provinsi Kalimantan Utara kurang optimal, dikarenakan :

1. Hasil penelitian Model Kemitraan Jaring Kerja, mengindikasikan belum semua stakeholder yang terlibat memahami kewenangannya masing-masing. Dinas Kehutanan selaku pengelola teknis berdasarkan Perda 12/95 dan KepBup 62/98 Pasal 3 telah menjalankan fungsi kerjanya dengan cukup baik, beberapa program yang dilaksanakan secara prosedural telah banyak melibatkan beberapa instansi kedinasan lainnya dan LSM, namun sejak proses ganti rugi lahan yang terdampak Hutan Kota Bunda Hayati dari Tahun 2002 hingga 2009, kewenangan kerja yang dimiliki oleh instansi Dinas Kehutanan Kabupaten Bulungan menjadi terbatas. Sedangkan dasar hukum kewenangan pengelolaannya belum sama sekali diperbaharui hingga sekarang.

2. Hasil penelitian Model Kemitraan Solid mengindikasikan pembangunan, pengembangan dan pengelolaan Hutan Kota Bunda Hayati Tanjung Selor telah melalui proses perencanaan, yakni 
dengan mengandeng institusi Pendidikan Tinggi dari IPB untuk menyusun cetak biru (Blue print) / Master Plan Hutan Kota Bunda Hayati dengan beberapa program prioritas. Namun, sekali lagi proses tersebut tidak berjalan sebagaimana mestinya, salah satunya adalah belum adanya ketetapan pengelolaan anggaran tersendiri yang diperuntukan pada SKPD Dinas Kehutanan Kabupaten Bulungan, sifat anggaran yang ada hanya berupa anggaran rutin kedinasan tidak mengatur secara spesifik terkait anggaran pengelolaan Hutan Kota Bunda Hayati. Sedangkan proses pembangunan yang dilaksanakan selama ini seperti pembangunan saluran drainase, pemagaran dan pembersihan / perawatan Hutan Kota Bunda Hayati tidak dikelola oleh Dinas Kehutanan.

3. Hasil penelitian ini mengindikasikan bahwa penerima manfaat dari pengelolaan dan pengembangan Hutan Kota Bunda Hayati belum dirasakan secara maksimal oleh masyarakat, utamanya dunia pendidikan tinggi. Tumpang tindihnya permasalahan yang muncul seputar pengelolaan dan pengembangan Hutan Kota Bunda Hayati Tanjung Selor hingga memasuki Tahun 2016 belum terselesaikan secara baik, termasuk kondisi status tanah kepemilikan Hutan Kota yang ada saat ini.

\section{DAFTAR PUSTAKA}

\section{BUKU}

Ahmadi, Abu \& Widodo, Supriyono. Psikologi Belajar. Jakarta: PT

Rineka Cipta, 2004 Azwar, Saifuddin, 2002, Sikap Manusia, Teori dan

Pengukurannya, Yogyakarta: Pustaka

Pelajar, 1969.

Bacon, Edmun. Design of The Cities, dalam Zahnd. Perancangan Kota

Terpadu. Jakarta: Kanisius, 1978.

Levinger, Beryl and Jean Mulroy. A Partnership Model for Public Health:

Five Variables for Productive Collaboration, Pact Publications

Washington DC. 2004

Budihardjo, Eko. Tata Ruag Perkotaan. Bandung: Alumni, 1997.

Budihardjo, Eko dan Sujarto, Djoko. Kota Berkelanjutan. Bandung:

Alumni, 1999.

Fandeli, C. Pola Pengelolaan Hutan Kota dan Kualitas Lingkungan.

Jakarta: Duta Rimba, 1990. 
Gilbert, Alan et al. 1984. Community Antisipation in Upgrading Irreguler Sattlement The Comumunity Response. World Development. Vol.12.No.8 page 769-782.

Hall, antonyet al. Community Participation, Social Develompent and State. London: Methven, 1986.

Hasan. Pokok-pokok Metodologi Penelitian dan Aplikasinya. Jakarta :

Ghalia Indonesia, 2002. Keraf, Sonny. Etika Lingkungan, Jakarta:

Kompas, 2002.

Lee F, Yok Shiu. 1994. Community Based Urban Environmental

Management: Local NGOs as Calalys. Regional Development

Dialoque. Autumn.Vol.15.No.2.

Lofland, John dan Lyn H. Lofland. Analyzing Social Setting: A Guide to

Qualitative Observation and Analysis. Belmont, Cal: Wads worth

Publishing Company, 1984

Marbun, B.N. Kota Indonesia Masa Depan, Masalah dan Prospek, Jakarta: Airlangga, 1994.

Moehaji, Noeng. Metodologi Penelitian Kualitatif. Yogyakarta: Rake Sarasin, 2000. Moleong, Lexy. Metodologi Penelitian Kualitatif.

Bandung: Remaja Rosdakarya, 2000.

M. Subana dan Sudrajat. Dasar-dasar Penelitian Ilmiah. Bandung: Pustaka setia, 2001.

Narbuko,C. dan Abu Achmadi, Metodologi Penelitian, Jakarta:P.T.

Bumi Aksara. 2002. Nasution. Metodologi Penelitian. Jakarta:

Penerbit Bumi Aksara, 2002.

Nazir, Mohamad. Metode Penelitian. Jakarta: Ghalia Indonesia, 1998.

Nazaruddin. Penghijauan Kota. Jakarta : PT.Penebar Swadaya. Panudju, Bambang. 1999. Pengadaan Perumahan Kota dengan peran serta Masyarakat dengan berpenghasilan rendah. Bandung: Penerbit Alumni, 1994.

Notoatmodjo, Soekidjo. Promosi Kesehatan dan Ilmu Prilaku. Jakarta:

Rineka Cipta, 2007 Notoatmodjo, Soekidjo. Metodologi Penelitian

Kesehatan, Jakarta: Rineka Cipta, 2002 Nurul, Zuriah. Metode

Penelitian Sosial dan Pendidikan, Teori-Aplikasi. Jakarta: Bumi

Aksara, 2007

Peter Evans. Livable Cities. Los Angeles.:Berkeley, 2002.

Rahmi, D.H dan Stiawan.B. Perancangan Kota Ekologi. Derektorat Jendral Pendidikan Tinggi Departemen Pendidikan dan Kebudayaan. Jakarta Sanoff, Henry.2000. Community Participation 
Methods In Design and Planning.New York: John Wiley and Sons Inc, 1999.

Rangkuti, Siti Sundari. Hukum Lingkungan dan Kebijaksanaan Lingkungan Nasional, Air Langga University Press, 2000. cet. Kedua

Sevilla,Consuelo, et al., Alih Bahasa Tuwu Alimudin, , Pengantar Metode Penelitian, Jakarta: Penerbit UI Press, 1993.

Silalahi, Daud. Hukum Lingkungan dalam Sistam Penegakan

Hukum Lingkungan di Indonesia. Ed.3. Cet.1. Bandung: Alumni, 2001.

Slamet, Y. Pembangunan Masyarakat Berwawasan Partisipasi.

Surakarta:Sebelas Maret University Press, 1992.

Soerjani, Mohamad. Pembangunan dan Lingkungan : Meniti Gagasan dan Pelaksanaan Sustainable Development. Jakarta : IPPL, 1977.

Sudharto, Hadi,P. Dimensi Lingkungan Perencanaan dan Pembangunan. Gadjah Mada: Univesity Press, 2001.

Sudjana. Metode Statistika. Bandung: Tarsito, 1996.

Sugiyono. Metode Penelitian Administratif. Bandung: Alfabeta, 2004.

Wells, M., Brandon,K.1 and Hannah,L. 1992. People and Parks.Linking Protected Area Management with Local Communities. Washington,D.C: World Bank/WWF/USAID.

White,A.T., L.Z.Hale, Y. Renard and L.Cortesi.1994. Lessons to be learned from experience. In:"Collaborative and Communty Based Management of Coral Reefs". Connecticut: Kumarian Press. pp.107-120

Wiyanto (pada Workshop Pemberdayaan Masyarakat Pasca Proyek,2004) Takashi Inoguchi, Edward Newman et al. 2001. Kota dan Lingkungan: Pendekatan Baru Masyarakat Berwawasan Ekologi, Pengantar: Eko Budihardjo. Jakarta: LP3ES.

Zahnd, Markus. Perancangan Kota Secara Terpadu. Yogyakarta: Kanisius, 1999.

\section{JURNAL / PUBLIKASI ILMIAH}

Arstein, S.R. A Ledder of Citizen Participation. AP Jounal 35(4),216-24

Badan Pusat Statistik Kabupaten Bulungan, 2012. Buku Puth : Kabupaten Bulungan dalam Angka.

Buku Besar Perencanaan : Master Plan Hutan Kota Bundayanti Tanjung Selor, Dinas Kehutanan Kabupaten Bulungan dan PPLH ITB, 2008. 
Dinas Pertamanan DKI Direktorat Jenderal Pembangunan Daerah, Depdagri, Ruang Terbuka Hijau Kota. Jakarta, 1990. Laporan Dinas Pertamanan DKI 1988 - 1989.

Rahmania A., Rukhmana, Didi dan Mappangaja, A. Rahman. 2008.

Analisis Pelaksanaan Pemanfaatan Ruang Terbuka Hijau Kecamatan Bantaeng Kabupaten Bantaeng.

Sujarto, Djoko.1993. Beberapa aspek perencanaan wilayah dan kota. PWKITB

Setiadi,Rukuh dan Budiati,Lilin.1999. "Aplikasi Model Analisa Diskriminan: mengkaji

Persepsi dan opini Masyarakat di sekitar sungai Babon terhadap pembentukan Model Pengelolaan Lingkungan yang Bertumpu pada Pemberdayaan Masyarakat', Jurnal Pondasi Vol.5 No.2 Desember. Semarang:Universitas Islam Sultan Agung.

Sumarmi. 2006. Partisipasi Masyarakat dalam Pengelolaan Ruang Terbuka Hijau Pemukiman di Kota Malang. Jurnal Ilmu Administrasi Universitas SamRatulangi Menado Vol. 2 No. 3 Desember 2006, ISSN 1858-4977.

Sukmana, Oman. 2007. Konsep Penataan Dan Pengelolaan Ruang Publik Pada Wilayah Perkotaan (Studi di Wilayah Kota Malang). Naskah Publikasi : Lembaga Penelitian Universitas Muhammadiyah Malang. Mei 2007.

Syaodih, Ernady \& Weisyaguna, 2011. Strategi Penataan Ruang Terbuka Hijau (Studi Kasus Kota Bandung). Prosiding LPPM Universitas Islam Bandung. Vol. 2 No. 1 ISSN 2089-3582.

William, W.Cris.1997. Partnership,Power and Participation.The United Nation Center for Human Sattlement. Vol.3. No.5 March.

\section{TESIS, DESERTASI}

Budiati, Lilin. Manajemen Partisipatif dalam Pengelolaan Lingkungan Studi Kasus di Sungai Babon Semarang. Tesis Program Pasca Sarjana Magister Managemen. Universitas Diponegoro. Semarang, 2000 .

Maniquin, José Manuel. Konsep Penyediaan Ruang Terbuka Hijau (RTH) Di Kota Dili Timor Leste. Program Magister Institut Teknologi Sepuluh Nopember Surabaya. Surabaya, 2011.

Ndaru Nugroho, Gunung Haryadi. Peran Pengembang Perumahan Dalam Pengelolaan Ruang Terbuka Hijau Di Perumahan Kemang Pratama 
Kota Bekasi. Masters thesis, Universitas Diponegoro Semarang. Semarang, 2010.

Wulandari, Emma. Karakteristik dan model partisipasi masyarakat dalam pengelolaan ruang terbuka hijau permukiman sangat sederhana di Kelurahan Tunggulwulung Kecamatan Lowokwaru Kota Malang. Tesis Program Pascasarjana Universitas Negeri Malang. Malang, 2007.

Wijanarko, Bambang. Kemungkinan Penerapan Co-Management Dalam Pengelolaan Ruang Terbuka Hijau Di Pantai Utara Kota Surabaya. Masters thesis, Program Pasca Sarjana Universitas Diponegoro. Semarang, 2006. 